\title{
Measuring regional social inclusion performances in the EU: Looking for unity in diversity
}

Journal of European Social Policy $1-20$

(C) The Author(s) 2018

Article reuse guidelines: sagepub.com/journals-permissions DOI: I0.1 I77/09589287|8792। 35 journals.sagepub.com/home/esp @SAGE

\author{
Nicky Rogge and Ryan Self \\ KU Leuven, Belgium
}

\begin{abstract}
This study measures and benchmarks regional social inclusion performances in Europe using a composite index constructed on the basis of the commonly agreed sub-indicators of the Europe 2020 headline indicators. The multidimensional nature of these issues and the disparate social policy priorities of nations/ regions in addressing them call for a reconciliatory performance evaluation framework, for which this article advocates the use of benefit-of-the-doubt $(B \circ D)$ weighting. Based on the composite scores, leading and lagging regions in social inclusion are identified and the impact of regional contextual characteristics is examined. Overall results show that regions of Denmark and Sweden are consistently strong performers, while the Continental regions of Italy and Spain typically perform poorly. As to the poverty and social exclusion determinants, results show that low educational attainment and a high percentage of singleparent households relate negatively to regional social inclusion.
\end{abstract}

\section{Keywords}

Benefit-of-the-doubt, composite indicators, conditional BoD model, Europe 2020, European Union, regional social inclusion

\section{Introduction}

For the European Union (EU), deepening social inequities represent a very real threat to the wellbeing of many of its citizens, with so many left behind as overall European prosperity increases. The European Commission voiced their growing concern through the announcement of the Europe 2020 initiative - a 10-year plan for 'smart, sustainable and inclusive growth' - which included an inaugural, EU-wide, headline indicator dedicated to tackling the issues of poverty and social exclusion throughout the 28 Member States (Armstrong, 2012). Placed on an equal footing with economic stability and competitiveness - traditionally the foremost aspects of the EU agenda - as one of five headline targets, the EU pledged to collectively lift 20 million people out of poverty and social exclusion by 2020 , amounting

\section{Corresponding author:}

Nicky Rogge, Faculty of Economics and Business, KU Leuven, Onderzoeksgroep Economie (ECON), Campus Brussel,

Warmoesberg 26, B-1000 Brussels, Belgium.

Email: Nicky.rogge@kuleuven.be 
to approximately 17 percent of those suffering in total (Eurostat, 2016). To help underpin the heightened commitment to the social dimension and better understand prevailing trends, the European Commission pays close attention to the progress of the Member States, measuring and monitoring their social inclusion performances on a regular basis with a view to streamlining social inclusion objectives and benchmarking. Presently, the EU determines social inclusion performance via a portfolio of social data, published by Eurostat through a broad set of social indicators based on advanced reporting and data collection standards. Three of these social indicators are used to construct a composite indicator, the at-risk-of-poverty or social exclusion (AROPE) index of the Europe 2020 framework. Under the soft-governance framework of the Social Open Method of Coordination (OMC), Member States are at liberty to peg their social inclusion quota to either the aggregated (composite) indicator AROPE or one (or a combination) of the three indicators (Social Protection Committee, 2011, 2012, 2015). The option even exists to invoke an alternative metric from the overarching portfolio, such as in the case of the United Kingdom, who opt to use an indicator measuring child poverty. ${ }^{1}$

The relative merits and demerits of composite indicators in measuring complex policy phenomena are well documented in the literature. Maitre et al. (2013) refer to the 'vigorous debate' among academics, in which proponents advocate the value of simple, comparable composite performance scores in benchmarking countries and/or regions against one another. Conversely, it is also held that the process of assigning weights to and aggregating different indicators risks oversimplifying complex phenomena such as social inclusion to the point where critical themes can be concealed, disguised or omitted altogether (Ravallion, 2011). ${ }^{2}$ The trade-off between these two standpoints represents an especially problematic hurdle for the EU to overcome when ranking Member States in a league table-like format (Robinson and Oppenheim, 1998; Zeitlin, 2008), where contextual differences and a sensitive evaluation environment can seriously undermine the credibility of any subsequent findings. Moreover, the multifaceted nature of social issues (poverty, social exclusion, etc.) as quantifiable concepts and the broad disparities between and within EU Member States both call into question the viability of a purely national approach to measuring and evaluating social inclusion performances. Particular reference in the academic literature can be made to the recommendations of Atkinson (2002) and Atkinson et al. (2004) who call for regional breakdowns of social inclusion performance indicators as a means of better understanding causal mechanisms and implementing targeted policy responses, especially in a context of increasingly devolved social policy at regional level. Similarly to the academics, Member States (and regions) hold rather diverse views as to what constitutes poverty or social exclusion domestically. Notable differences exist between even neighbouring countries, as discussed by Madanipour et al. (2015) who, among others, also point to fundamental differences between the different regions of a given nation. Second, as to the construction of the AROPE index, discussion exists over the use of uniform, equal weighting in aggregating the sub-indicators. Atkinson et al. (2004), among others, observe an innate appeal in equal weighting, which is often justified by the parsimony of Occam's razor - that the simplest among otherwise equal models represents the best choice - treating each indicator as equally significant for all evaluated Member States (or regions) in the absence of concrete evidence to suggest otherwise. However, there are also other academics who argue that in light of the heterogeneity of social exclusion and the degree to which indicators matter to the countries and regions in different proportions, it is best to allow the importance weights of the indicators in the construction of the composite indicator to vary across regions and countries, taking into account local and regional preferences (Pasha, 2017; Whelan and Maître, 2013).

The main aim of the article is to compute a composite indicator for measuring regional social inclusion performances in the EU on the basis of the three commonly agreed sub-indicators of the Europe 2020 AROPE index. As noted above, quantifying a multifaceted concept such as social inclusion is rather complex, and doing so on a European scale with a wide dispersion of backgrounds across countries and regions, amid disagreement between stakeholders 
and experts on the true importance weights of the indicators, represents some obvious and major methodological and practical difficulties. ${ }^{3}$ As a viable solution to these challenges, this study advocates the use of the conditional benefit-of-the-doubt (BoD) weighting methodology (Cherchye et al., 2007). It is argued that the optimistic nature of the BoD methodology works particularly well in conjunction with the philosophy of the Social OMC, as regions are at liberty to pursue success in one particular direction without being overly penalized for poor performance in another (less relevant) aspect (Ferrera et al., 2002). Another objective of the article is to provide answers to several policy-relevant research questions. In particular, the BoD-based composite indicators for regional social inclusion are used to identify topperforming regions in promoting social inclusion, which can define best practices for other regions to mimic. In addition, the article will explore the social inclusion performance realized by regions within the same Member State so as to examine whether these regional performances are largely similar or whether there is considerable interregional disparity.

The article contributes to the literature in several ways. The first contribution lies in measuring social inclusion performances in the EU, nominally by aggregating the three commonly agreed regional social indicators into a composite indicator using the aforementioned BoD method. The second contribution of this article relates to the focus on regional performances. Previous studies employing similar approaches to EU social inclusion evaluation, such as Cherchye et al. (2004), Rogge (2017), Giambona and Vassallo (2014) and Rogge and Konttinen (2017), have focused on social inclusion performances at the level of the EU Member States. Although these studies offer some interesting and useful insights, it could be argued that the epistemological potential of evaluating social inclusion performance is diminished through the retention of relative, national-level indicators and that a more indepth regional-level breakdown of poverty and social exclusion unearths critical knowledge of determinants and, significantly, possible solutions for these issues (Longford et al., 2010; Stewart, 2003). The scope of this analysis, then, delves beyond national performance evaluation to examine and account for the regional variation of social inclusion, with a specific interest in the second level of the Nomenclature of Territorial Units for Statistics (NUTS-2 level). ${ }^{4} \mathrm{~A}$ third contribution is that the article examines how regions' contextual characteristics are related to their estimated composite social inclusion scores. This facilitates a study of (1) whether the contextual characteristics are on average statistically significantly related to the social inclusion performance of NUTS regions, and (2) whether this relationship is favourable or unfavourable for the average NUTS region.

The article also contributes to the policy debate on social inclusion in the EU in two ways. First, the composite index as constructed in the article summarizes the social inclusion performance for each country and region. As such, it provides policymakers with a picture of the regional social inclusion performance as measured based on the latest regional social data. Second, the BoD weighting method used in the construction of multidimensional composite index helps decision makers by drawing attention to particular issues, identifying benchmark regions and setting policy priorities.

The article will progress in the following manner. The second section briefly discusses the issue of poverty and social exclusion in the EU as well as the current social policy framework and initiatives. The following section describes the data comprising the regional social inclusion AROPE index and the background variable data set. Subsequently, the fourth section explains the construction and functionality of the BoD-weighted models, before discussing results outcomes and observations in the fifth section. The article concludes in the final section with a discussion of the prevailing themes of the BoD computations, with relevant reservations and corroboration of the issues presented in the literature and throughout the article. The concluding section ends with a discussion of some topics for further research.

\section{Poverty and social exclusion in the EU}

The crescendo of social policy in the EU over recent decades has led to heightened awareness in political 
and academic circles, and a proliferation of reporting has accordingly followed. Definitions of poverty abound and continue to divide opinion among experts and scholars on a conceptual and normative level. Nonetheless, a consensus does now exist on the notion that poverty is a multidimensional phenomenon. Indeed, the modernized term 'social exclusion' is held to represent a broader set of parameters than poverty alone and has become a more pragmatic term for the multifaceted social issues faced by the EU today as a whole. The concept of social exclusion is found to better capture 'the multidimensional nature of the mechanisms whereby individuals and groups are excluded from taking part in the social exchanges, from component practices and rights of social integration' (European Commission, 1992: 8), thus extending beyond purely financial aspects to include elements such as education, housing, health and employment, all of which have resonated heavily in the EU's social policy initiatives since the turn of the century. For further reading on the different interpretations of poverty and social exclusion only briefly touched upon here, readers can refer to Béland (2007) and Room (1999), among others.

By all accounts, the Europe 2020 strategy represents a meaningful step towards overcoming poverty and social exclusion in the EU through the insertion of an (ambitious) EU-wide, headline poverty and social exclusion target (Armstrong, 2012). That is not to say that social exclusion is an entirely new concern for the EU, but it was not until the turn of the century and the conception of the universally agreed, multidimensional Laeken Indicators that a modernized social dimension within the EU was properly established. These Laeken Indicators were tantamount to the social enterprise of the Lisbon Strategy launched in 2000, which has been credited by, among others, Armstrong (2012) and Zeitlin (2008) as the pioneering initiative that shaped the attitudes towards poverty and social exclusion in the EU for the future. Not least of which in this regard were the formalizations of the Social Protection Committee (SPC), the National Action Plans (NAPs) and most pertinently, Social OMC; in lieu of legitimate EU competence to implement social policy, the OMC's role in supporting, monitoring and benchmarking the Member States in their respective campaigns against social exclusion is paramount (Ferrera et al., 2002; Madanipour et al., 2015). In essence, the OMC constitutes a framework of soft governance with the remit of regulating EU-wide efforts towards the various social inclusion targets, promoting cooperation between Member States in the pursuit of their respective goals. This working philosophy reinforces the subsidiarity principle towards policy-making in the EU - a product of the breadth of circumstances and social systems across the nations and regions.

Europe 2020's agenda builds upon the successful elements of its predecessor, the Lisbon Treaty, and attempts to further modernize the social dimension within Europe by establishing a governance mechanism with a more assertive stance in social policymaking. To address one of the main criticisms of the Lisbon Treaty, primarily a lack of institutionalization towards social policy efforts, the European Commission launched an array of supplementary programmes to assist in achieving its goals. First, seven 'flagship initiatives' were launched to underpin and support the headline targets and the work of the OMC. Two of these initiatives pertain directly to the social target of Europe 2020, specifically the Youth in Action Programme of the European Commission and the European Platform against Poverty and Social Exclusion (EPPS). The former focuses on increasing youth employment by promoting mobility, intercultural dialogue, non-formal learning and inclusion and by supporting youth workers and civil society organizations through networking and training. The EPPS is designed mainly to help EU Member States in realizing the Europe 2020 social targets and ensuring economic, social and territorial cohesion, particularly through the identification of regions and demographics in the EU most susceptible to deprivation and social exclusion. Second, the boosting of financial instruments such as the European Regional Development Fund (ERDF) and the Cohesion Fund of the EU (CF) has provided greater support to areas suffering most from the effects of the financial crisis. Finally, the dashboard of indicators used to measure and monitor the progress of the Member States and their regions was overhauled in order to streamline social exclusion objectives and benchmarking - this last 
point is a core element of this study and will be discussed accordingly in the subsequent sections (SPC, 2012).

\section{Data}

\section{Regional social inclusion data}

Eurostat periodically publishes a broad portfolio of national and regional social data based on advanced reporting and data collection standards. A part of this data is retrieved from the EU-Statistics on Income and Living Conditions (EU-SILC) survey which discloses data on a wide variety of social issues, including the three sub-indicators used to construct the Europe 2020 AROPE index. In essence, this AROPE index is a composite index which involves an equally weighted totting up of the population suffering from at least one of the three types of poverty, expressed as a percentage of the total population. The three types of poverty are measured by the following three social sub-indicators: (1) at-risk-of-poverty rate $(A R O P)$ which is defined as the share of persons with an equivalized disposable income below 60 percent of the national equivalized median income (after social transfers), (2) severe material deprivation rate which gauges the share of population living in households lacking four (or more) of a list of nine items commonly considered to be basic goods or necessities $^{5}$ and (3) the low-work-intensity household rate which accounts for the persons aged 18-59 living in a household in which those eligible for the labour force worked under 20 percent of their potential over the course of the previous year. Note that the three social indicators measure social exclusion, that is, higher scores (percentages) represent negative performance (also known as 'bads'). However, as the basis of this study is to assess social inclusion, this necessitates the conversion of the indicators into 'goods', which is achieved by subtracting the value score from 100 , so a 10 percent social exclusion rate would equate to a 90 percent social inclusion rate.

The data for this study include social inclusion indicators for 176 'regions', of which 108 are categorized as NUTS-2-level, 51 as NUTS-1-level and 17 as NUTS-0-level regions. There are 32 countries recorded in the data set (the 28 EU Member States plus Switzerland, Iceland, Turkey and Norway), of which seven themselves, due to size and/or population, constitute NUTS-2-level regions (Cyprus, Estonia, Iceland, Latvia, Lithuania, Luxemburg and Malta) and eight NUTS-1-level regions (Croatia, the Czech Republic, Denmark, Ireland, Norway, Slovakia, Slovenia and Switzerland). Of the 17 NUTS-0-level countries, six do not disclose any further regional data breakdowns (Austria, France, Germany, Portugal, Turkey and the United Kingdom) and a further five disclose only up to NUTS-1 level (Belgium, Greece, Hungary, the Netherlands and Poland). The remaining six countries (Bulgaria, Finland, Italy, Romania, Spain and Sweden) provide social data breakdowns to NUTS-1 and NUTS-2 level. As such, these latter 11 regions feature in the sample alongside at least one subsequent level of their constituent NUTS regions. Similarly, there are 29 NUTS-1-level regions included in the sample (Czech Republic, Denmark, Ireland, Norway, Slovakia, Slovenia and Switzerland) for which the deeper NUTS-2-level regional data are also available and disclosed. The collected data cover the year 2015, for which the most recent, complete data set is presently available.

The decision to include all available social inclusion data (NUTS-2-level, NUTS-1-level and NUTS0 -level regions) can be attributed to three reasons. One reason is that a complete NUTS-2-level analysis is unfortunately not permitted by the data. The disclosure of regional data has not (yet) been made compulsory by the European Commission, and as a result, several Member States do not disclose NUTS2-level social inclusion data (or even NUTS-1-level data). The absence of (reliable) regional social data has been a long-standing shortcoming of the EU's social policy reporting standards, as noted by a number of academic studies (Atkinson et al., 2004; Stewart, 2003). A second reason is that across EU Member States political responsibility for social policy-making is typically situated at different political levels. By the same token, it is also the case in several Member States that political responsibility is dispersed across multiple political levels. This makes the evaluation of social inclusion performances in the EU a very intricate matter, given that national and regional social inclusion performances are at 
least to some extent intertwined. Including the social inclusion data available at the different NUTS levels limits the risk of missing out on social inclusion performance information. A third reason is more pragmatic and relates to the $\mathrm{BoD}$ method. In particular, including the performance data of the NUTS regions' territorial 'superiors' does not have a significantly distorting effect on the results due to the mechanics of the conditional BoD framework used to estimate the regional social inclusion scores (with regions being compared to regions with similar contextual characteristics, that is, the notion of comparing 'like with likes'; see the fourth section). On the contrary, expanding the sample size enhances the benchmarking process and the potential for unearthing trends, as well as offering a number of additional angles for analysis (e.g. making national-level comparisons or a national-level region vis-à-vis the performances of its respective local NUTS regions). ${ }^{6}$ This also explains the inclusion of the four non-EU countries (Switzerland, Iceland, Turkey, Norway) - three of which disclose data down to NUTS-2 level. Of course, the limited availability of regional data for some countries is disappointing and far from ideal with respect to this study. Well-documented regional disparities such as the United Kingdom's and Germany's respective North-South and East-West divides must consequently be overlooked. ${ }^{7}$ Instead, for the countries where regional data are lacking, there is no other choice but to consider only the national data as a marker for all NUTS-2-level regions in that country.

\section{Regional contextual characteristics}

To account and correct for the entrenched socio-economic conditions of each region in the evaluation of the regional social inclusion performances (see the conditional BoD model in the fourth section), five contextual characteristics are selected which, according to the relevant academic literature, can be considered as determinants of poverty and social exclusion. The first contextual characteristic is the age-dependency ratio as disclosed by Eurostat's unified demography project (UNIDEMO) which represents the proportion of the population aged 0-19 and $60+$ relative to those aged between 20 and 59, that is, the working population. The supposition is that a region with a high age-dependency ratio is effectively handicapped when competing with other regions with relatively fewer pensioners and youths to those of working age - all else equal (Eurostat, 2016; Guio et al., 2010). The recent Eurostat report (Eurostat, 2016), for instance, finds that an ageing population puts a large strain on the labour force and as such a considerable burden on the welfare state and economic condition of a region as a whole. This higher pressure indirectly exacerbates the conditions for societal groups threatened by poverty and social exclusion (Eurostat, 2016). The second contextual characteristic is the single-parent households variable which quantifies the number of households comprising a single parent living with at least one dependent child, as a percentage of all recorded households. As with the previous variable, one might expect it is more difficult for regions with a higher number of single-parent households to perform well in promoting social inclusion - all else being equal. This intuition is derived from empirical evidence collected by previous studies (Eurostat, 2016; Guio et al., 2010) showing that single-parent households face a much greater risk of poverty and social exclusion than other household compositions (e.g. households with two adults and children or single households without children). The recent Eurostat (2016) report revealed that nearly 50 percent of single-parent households were at risk in 2014, almost twice the EU average and higher than any other household type. A third exogenous characteristic is the educational attainment variable which constitutes a 'bad' by capturing the percentage of the population that are educated only up to level 2 on the ISCED (International Standard Classification of Education) scale (lower secondary education or lower). The intuition here is that regions with a greater presence of low education are disadvantaged in promoting social inclusion compared to other regions with lower levels of low education. Naturally, education has a sizeable impact on an individual's career prospects, role in society and, by extension, vulnerability to poverty or social exclusion in later life (Atkinson et al., 2004). Referring to the figures in Eurostat's (2016) report, juxtaposed to the 12 percent of people with ISCED level 3 education, a 
significant 35 percent of people with (at most) level 2 were at risk of poverty or social exclusion - almost three times more likely. In the most extreme cases, such as the Czech Republic, those belonging to the lowest education bracket were up to six times more at risk than those with the highest educational achievement in 2014 (Eurostat, 2016). A fourth contextual characteristic is household income. This variable is drawn from the Regional Accounts Survey of Eurostat and measures the average purchasing power consumption standards per inhabitant as a percentage of the EU average. It is generally considered as a useful gauge for evaluating relative wealth among the regions of Europe. The notion is that generally less-wealthy nations, mainly the Eastern European and Balkans States, will be less successful in combating social exclusion relative to the richer Member States such as in Scandinavia (Longford et al., 2010). The final contextual characteristic is gender. It concerns a dummy variable with a female majority returning a value of 1 (and 0 for a male majority). ${ }^{8}$ As reported by Eurostat (2016) and Guio et al. (2010), women face a greater risk of poverty and social exclusion than men. The intuition is, thus, that regions with a majority of women are more prone to poverty and social exclusion.

Note that the selection of the five contextual characteristics is constrained by the availability of NUTS-2-level data or lack thereof. Indeed, a number of telling determinants of poverty and social exclusion have been identified in the literature for which regional data are not yet disclosed, notably concerning migration, urbanization and health/disability, among others (Eurostat, 2016; Guio et al., 2010). For instance, studies showed that low-skilled immigrants (ethnic minorities and immigrants) who are not (or not adequately) assimilated in their host country are at risk of being socially excluded. Studies have also found that people who suffer from health problems or disabilities have a higher risk of being socially excluded. Coromaldi and Zoli (2012) demonstrated that a person's labour market status significantly affects the chances of being deprived and socially excluded. Particularly, the long-term unemployed are at risk of being gradually pushed out of their social networks. All of this suggests that regions with (1) less well-functioning labour markets, (2) a higher number of ethnic minorities and immigrants and (3) a higher number of people with health issues and/or disabilities are disadvantaged in promoting social inclusion compared to other regions. If regional-level data for such indicators were disclosed in the future, it would be interesting to integrate them in the present analysis. We consider this as an interesting topic for future research.

\section{BoD weighting}

The BoD weighting method lends itself to the task of measuring regional social inclusion performances. As with typical composite indicator, in order to obtain summative policy performance scores, the BoD model seeks to aggregate the three regional social indicators into a single, comparable performance score. In the specification of the importance weights for the indicators, the BoD model allows the weighting scheme for each region to be endogenously determined by the social indicator data, by pitting the relative performances of each region in each indicator against all other regions in the sample to determine a weighting scheme which maximizes the composite indicator $(\mathrm{CI})$ value for each region. Simply put, the BoD model allows the flexibility to assign higher (lower) importance weights to social inclusion indicators in which stronger (weaker) relative performances for a region are observed. By doing so, the BoD model grants each region the 'benefit of the doubt' in the absence of true or known importance weights and evaluates a region's social inclusion performance in the best possible manner relative to the other regions' social inclusion performances. In formal notations, the following model (equation (1)) must be solved for each region $k$

$$
\begin{gathered}
C I_{k}=\max _{w_{k, m}} \sum_{m=1}^{M} w_{k, m} y_{k, m} \\
\text { s.t. } \\
\sum_{m=1}^{M} w_{k, m} y_{j, m} \leq 1 \forall j=1, \ldots, k, \ldots, N
\end{gathered}
$$




$$
w_{k, m} \geq 0 \forall m=1, \ldots, M
$$

with $y_{k}=\left(y_{k, 1}, y_{k, 2}, \ldots, y_{k, M}\right)$ being the indicators evaluating the $M$ aspects of social inclusion performance of region $k(m=1, \ldots, M$; in this case $M=3)$; $y_{j}=\left(y_{j, 1}, y_{j, 2}, \ldots, y_{j, M}\right)$ being region $j$ 's $M$ social inclusion indicators $(\forall j=1, \ldots, k, \ldots, N$; in this case $N=176$ regions); and $w_{k, m}$ being the BoD-estimated region-specific weights for $M$ social inclusion indicators. The basic version of the $\mathrm{BoD}$ model as in equation (1) imposes two minor constraints (Cherchye et al., 2007). The first restriction is the normalization restriction (equation (1a)) which imposes that optimal weights should be such that when applied to each region in the sample, all regions obtain a composite social inclusion score between zero and one. Thus, the most favourable weights for each evaluated region are always applied to all other regions in the sample. In that way, one effectively looks at which of the regions' social inclusion indicator values are such that they would lead to a worse, similar or better composite social inclusion score, when applying the most favourable weights for the evaluated region. In the interpretation of the composite social inclusion scores, higher score values indicate a better overall social inclusion performance for the region. Regions who return a composite social inclusion score of one thus act as their own benchmark, then, as they cannot be outperformed by any other region present in the sample with their own BoD-estimated importance weights. Regions for which the $\mathrm{BoD}$ model generates a composite social inclusion score lower than one are clearly outperformed given that, despite the fact that one allows for region-specific $\mathrm{BoD}$ weights, there is then still at least one other region in the sample which, using the same weighting scheme, does even better. A second constraint (equation (1b)) is the nonnegativity constraint which imposes non-negativity of the BoD-estimated optimal importance weights for the social inclusion indicators and, hence, monotonicity in the construction of the composite index.

The basic version of the BoD model as in equation (1) is further amended in two ways. First, in order to avoid that the BoD model assigns unrealistic and/or improper importance weights (very low or even quasizero weights) for the social inclusion indicators and thereby inflating the perceived social inclusion performance of a region, an additional weight restriction is implemented which imposes that BoD-estimated importance weights should be at least 10 percent. Ideally, such lower weight bound values should be specified by experts and/or stakeholders. However, in the current setting, expert information on the importance of the social inclusion indicators is lacking. Nevertheless, we adopt the minimalist position that all social inclusion indicators provide at least some valuable information to the measurement of regional social inclusion. Second, a conditional version of the BoD model is developed to accommodate for the contextual characteristics of the regions in the estimations of their composite social inclusion score (following insights of Daraio and Simar, 2007). That is, whereas the BoD model as set out above estimates each region's social inclusion performance vis-à-vis all regions in the sample, dissimilarities in contextual characteristics notwithstanding, the basic idea of the conditional version of the BoD model is to evaluate the social inclusion performance of each region relative to the performances of regions with similar contextual characteristics (in this case, the five contextual variables discussed in the second part of the third section). ${ }^{9}$ In the interpretation of the conditional composite social inclusion scores, scores higher than one denote that the region $k$ exceeds the level of social inclusion performance expected from a region with similar contextual characteristics. The opposite holds for a composite score lower than one. An estimated composite score equal to one designates that region $k$ has a social inclusion performance similar to the social inclusion performance realized by the average region with comparable contextual characteristics.

The nature of the BoD methodology in its construction brings several practical benefits in its application to the measurement and monitoring of regional social inclusion performances in the EU. First, the sensitivity of comparing regional social inclusion performances within the EU necessitates the use of a universally agreeable strategy that simultaneously captures vital information and permits policy prioritization. Under the remit of the social OMC's subsidiarity principle, BoD weighting promotes goal congruence between respective regions and the wider EU, in the sense that they are at liberty 
to contribute to the overall headline target via their own individual means, without wholly ignoring other aspects commonly agreed to be relevant. Policymakers are entitled to pursue the most relevant aspects of social inclusion without concern for lower overall social inclusion policy performance scores on what might be perceived as arbitrary performance criteria. Second, due to the optimistic scoring system - the most flattering review possible - disappointed performers are disarmed from blaming an ill-fitting or unfair weighting scheme as the cause of their poor aggregated performance score. It becomes difficult to justify claims of disadvantage from the weighting system given that any other weighting scheme would only diminish their overall relative performance score. The direct comparison of regions makes for a sensitive evaluation environment, especially in the delicate and increasingly important topic such as that of social inclusion, so affording regions the benefit of the doubt in lieu of more concrete information appears to be a suitable concession towards a more harmonious evaluation process. Third, as the comparison of vastly disparate regions seems a somewhat redundant exercise in the context of common goals and serves little value in policy guidance or working towards a more convergent social Europe, the conditional version of the BoD model compares only 'like with like' (i.e. regions with largely similar contextual characteristics), in the computation of regions' composite social inclusion performance scores. This makes it harder for dissatisfied regions to reject their score or rank, as they cannot blame their lower composite score to uneven starting positions or dissimilar contextual characteristics. A fourth benefit is an analytical advantage related to the use of the conditional BoD model. More particularly, the conditional variant of the BoD model allows for non-parametric statistical inference of the relationships between the regions' contextual characteristics and the estimated composite social inclusion scores. This facilitates a study of (1) whether the regional contextual characteristics are on average statistically significantly related to the regional social inclusion performance, and (2) whether this relationship is favourable or unfavourable for the average region. Moreover, (partial) regression plots make it possible to visualize how each contextual characteristic relates to the regional social inclusion performance scores, all else being equal. ${ }^{10}$ This information is especially valuable for regional policymakers as it provides at least a partial explanation in the event of disappointing performance scores.

\section{Results}

Seeing as the composite performance indicator used in this article is founded upon the established Europe 2020 AROPE index insofar as it consists of the same three social indicators, an interesting point of reference is available for assessing the interaction of the BoD model with the social inclusion data. Two selections of results are presented and discussed in this section. Table 1 displays a full overview of country scores and ranks for both the EU's AROPE index and the conditional BoD-weighted social inclusion composite indicator, as well as the intervening rank changes (relative to the AROPE rank). The index scores for the countries are either derived from the regional social inclusion performance scores or using the national-level social indicator data (in cases where no regional social inclusion data are available). Table 2 displays the AROPE index and the BoDestimated composite social inclusion scores and ranks for the NUTS-2 regions of three countries with traditionally varying regional composition: Sweden, the Czech Republic and Romania. For an overview of the AROPE index and the BoD-estimated composite social inclusion scores and ranks for all regions in the sample as well as their BoD-estimated optimal importance weights for the social inclusion indicators, see Supplementary Appendices 1 and 2. ${ }^{11} \mathrm{~A}$ visualization of the AROPE-scores and the conditional BoD-estimated regional social inclusion scores (both normalized between 0 and 1 values, with higher values indicating a better performance in social inclusion) is given in Figure 1.12

Before delving deeper into the national and regional social inclusion performances, we briefly discuss the descriptive statistics of the two versions of the composite index for regional social inclusion, that is, Eurostat's AROPE index $\left(A R O P E_{r}\right)$ and the conditional BoD-estimated social inclusion composite index $\left(C I_{r}^{z}\right)$, as displayed at the bottom of Table 1. In addition, a visual representation of the AROPE-scores 
Table I. The Europe 2020 AROPE index and conditional BoD-based composite index scores and ranks for the 28 EU Member States plus Iceland, Norway, Switzerland and Turkey.

\begin{tabular}{|c|c|c|c|c|c|c|}
\hline & EU country & AROPE & Rank & $C l_{k}^{z}$ & Rank & $\Delta$ \\
\hline AT & Austria & 18.3 & 10 & 0.9712 & 11 & -1 \\
\hline $\mathrm{BE}$ & Belgium & 21.1 & 15 & 0.9482 & 18 & -3 \\
\hline BG & Bulgaria & 41.3 & 31 & 0.8870 & 30 & +1 \\
\hline $\mathrm{CH}$ & Switzerland & 16.4 & 5 & 0.9868 & 7 & -2 \\
\hline CY & Cyprus & 28.9 & 25 & 0.9143 & 28 & -3 \\
\hline$C Z$ & Czech Republic & 14.0 & 2 & 0.9706 & 12 & -10 \\
\hline $\mathrm{DE}$ & Germany & 20.0 & 14 & 0.9607 & 14 & 0 \\
\hline DK & Denmark & 17.7 & 8 & 0.9786 & 9 & -1 \\
\hline $\mathrm{EE}$ & Estonia & 24.4 & 19 & 1.0000 & 2 & +17 \\
\hline EL & Greece & 35.7 & 29 & 0.8589 & 32 & -3 \\
\hline ES & Spain & 28.6 & 23 & 0.9281 & 23 & 0 \\
\hline $\mathrm{FI}$ & Finland & 16.8 & 7 & 0.9899 & 5 & +2 \\
\hline FR & France & 17.7 & 8 & 0.9753 & 10 & -2 \\
\hline HR & Croatia & 29.1 & 26 & 0.8884 & 29 & -3 \\
\hline $\mathrm{HU}$ & Hungary & 28.2 & 22 & 0.9276 & 24 & -2 \\
\hline IE & Ireland & 26.0 & 20 & 0.9283 & 22 & -2 \\
\hline IS & Iceland & 13.0 & I & 1.0002 & 1 & 0 \\
\hline IT & Italy & 28.7 & 24 & 0.9192 & 27 & -3 \\
\hline LT & Lithuania & 29.3 & 27 & 0.9268 & 25 & +2 \\
\hline LU & Luxembourg & 18.5 & 12 & 1.0000 & 2 & +10 \\
\hline LV & Latvia & 30.9 & 28 & 0.9352 & 21 & +7 \\
\hline MT & Malta & 22.4 & 16 & 0.9401 & 20 & -4 \\
\hline NL & Netherlands & 16.4 & 5 & 0.9830 & 8 & -3 \\
\hline NO & Norway & 15.0 & 3 & 0.9894 & 6 & -3 \\
\hline PL & Poland & 23.4 & 17 & 0.9535 & 16 & +1 \\
\hline PT & Portugal & 26.6 & 21 & 0.9481 & 19 & +2 \\
\hline RO & Romania & 37.4 & 30 & 0.9242 & 26 & +4 \\
\hline SE & Sweden & 16.0 & 4 & 0.9986 & 4 & 0 \\
\hline SI & Slovenia & 19.2 & 13 & 0.9627 & 13 & 0 \\
\hline SK & Slovakia & 18.4 & II & 0.9587 & 15 & -4 \\
\hline $\mathrm{TR}$ & Turkey & 51.2 & 32 & 0.8848 & 31 & +1 \\
\hline \multirow[t]{5}{*}{ UK } & United Kingdom & 23.5 & 18 & 0.9483 & 17 & +1 \\
\hline & Mean & 25.1 & & 0.9489 & & \\
\hline & $S D$ & 10.7 & & 0.0521 & & \\
\hline & Min. & 10.0 & & 0.7336 & & \\
\hline & Max. & 55.4 & & 1.0002 & & \\
\hline
\end{tabular}

SD: standard deviation; EU: European Union; BoD: benefit-of-the-doubt; AROPE: the Europe 2020 AROPE index; $C l_{k}^{z}$ : conditional BoD-estimated social inclusion performance score; $\Delta$ : change in rank relative to AROPE rank.

and ranks versus the conditional BoD-weighted social inclusion scores and ranks (the scores being normalized between 0 and 1 ) is provided in the scatterplots as in Figure 2(a) and (b), in order to gain an overall picture of how the combination of BoD weighting and accounting for contextual characteristics comes into play. As to the descriptive statistics of Eurostat's AROPE index $\left(A R O P E_{r}\right)$ and the conditional version of the BoD-estimated social inclusion composite indices $\left(C I_{r}^{z}\right)$, there are some interesting points to be 
Table 2. The Europe 2020 AROPE index and conditional BoD-based composite index scores and ranks for the NUTS regions of Sweden, Czech Republic and Romania.

\begin{tabular}{|c|c|c|c|c|c|c|}
\hline & NUTS region & AROPE & Rank & $\mathrm{Cl}_{\mathrm{k}}^{\mathrm{z}}$ & Rank & $\Delta$ \\
\hline SEII & Stockholm & 13.1 & 12 & 1.0002 & I & 11 \\
\hline SEI2 & Östra Mellansverige & 17.4 & 55 & 0.9946 & 39 & 16 \\
\hline SE2I & Småland med öarna & 16.6 & 39 & 0.9999 & 24 & 15 \\
\hline SE22 & Sydsverige & 17.6 & 57 & $0.994 I$ & 40 & 17 \\
\hline SE23 & Västsverige & 15.6 & 26 & 1.0000 & 20 & 6 \\
\hline SE3I & Norra Mellansverige & 17.3 & 52 & 1.0000 & 4 & 48 \\
\hline SE32 & Mellesta Norrland & 16.3 & 33 & 1.0000 & 4 & 29 \\
\hline \multirow[t]{2}{*}{ SE33 } & Övre Norrland & 17.3 & 52 & 0.9999 & 23 & 29 \\
\hline & NUTS region & AROPE & Rank & $\mathrm{Cl}_{k}^{\mathrm{z}}$ & Rank & $\Delta$ \\
\hline$C Z$ & Czech Republic & 14.0 & 14 & 0.9706 & 85 & -71 \\
\hline CZOI & Praha & 10.6 & 3 & 1.0000 & 4 & -1 \\
\hline CZO2 & Strední Cechy & 10.0 & 1 & 1.0000 & 4 & -3 \\
\hline CZO3 & Jihozápad & 11.2 & 5 & 0.9893 & 54 & -49 \\
\hline CZO4 & Severozápad & 21.7 & 90 & 0.9131 & 138 & -48 \\
\hline CZ05 & Severovýchod & 10.2 & 2 & 1.0000 & 4 & -2 \\
\hline CZ06 & Jihovýchod & 12.6 & 7 & 0.9909 & 44 & -37 \\
\hline CZO7 & Strední Morava & 16.4 & 34 & 0.9727 & 80 & -46 \\
\hline CZ08 & Moravskoslezsko & 21.7 & 90 & 0.9143 & 136 & -46 \\
\hline \multirow[t]{2}{*}{ RO } & Romania & 37.4 & 145 & 0.9222 & 127 & +18 \\
\hline & NUTS region & AROPE & Rank & $C I_{k}^{z}$ & Rank & $\Delta$ \\
\hline ROI & Macroregiunea unu & 29.7 & 127 & 0.9492 & 97 & +30 \\
\hline ROII & Nord-Vest & 28.0 & 118 & 0.9651 & 77 & +41 \\
\hline $\mathrm{RO} / 2$ & Centru & 31.6 & 133 & 0.9325 & 118 & +15 \\
\hline $\mathrm{RO} 2$ & Macroregiunea doi & 46.2 & 169 & 0.9148 & 132 & +37 \\
\hline RO2I & Nord-Est & 46.3 & 170 & 0.9327 & 117 & +53 \\
\hline RO22 & Sud-Est & 46.2 & 168 & 0.8890 & 149 & +19 \\
\hline $\mathrm{RO} 3$ & Macroregiunea trei & 34.4 & 139 & 0.9294 & 122 & +17 \\
\hline RO3I & Sud-Muntenia & 43.5 & 161 & 0.9063 & 140 & +21 \\
\hline RO32 & Bucuresti-Ilfov & 20.5 & 81 & 0.9897 & 33 & +48 \\
\hline RO4 & Macroregiunea patru & 37.6 & 147 & 0.8842 & 153 & -6 \\
\hline RO4I & Sud-Vest Oltenia & 41.9 & 157 & 0.8944 & 146 & +11 \\
\hline RO42 & Vest & 32.0 & 136 & 0.8730 & 158 & -22 \\
\hline
\end{tabular}

NUTS: Nomenclature of Territorial Units for Statistics; AROPE: the Europe 2020 AROPE index; BoD: benefit-of-the-doubt; $\mathrm{Cl}_{k}^{z}$ : conditional BoD-estimated social inclusion performance score; $\Delta$ : change in rank relative to AROPE rank.

taken away from these statistics. Looking first to the AROPE figures, large differences can be observed between the minimum and maximum AROPE-scores and, thus, the best- and worst-performing regions in terms of the AROPE. Moreover, the large standard deviation echoes the substantial regional disparity in social inclusion present in the sample. Turning to the descriptive statistics of the BoD-weighted social inclusion composite indices, a first observation is that the mean composite index score of 0.9489 indicates the average region still has some room for improving their social inclusion performance. The relatively high mean scores and low standard deviation (i.e. 0.0521) allude to the fact that the disparity between 


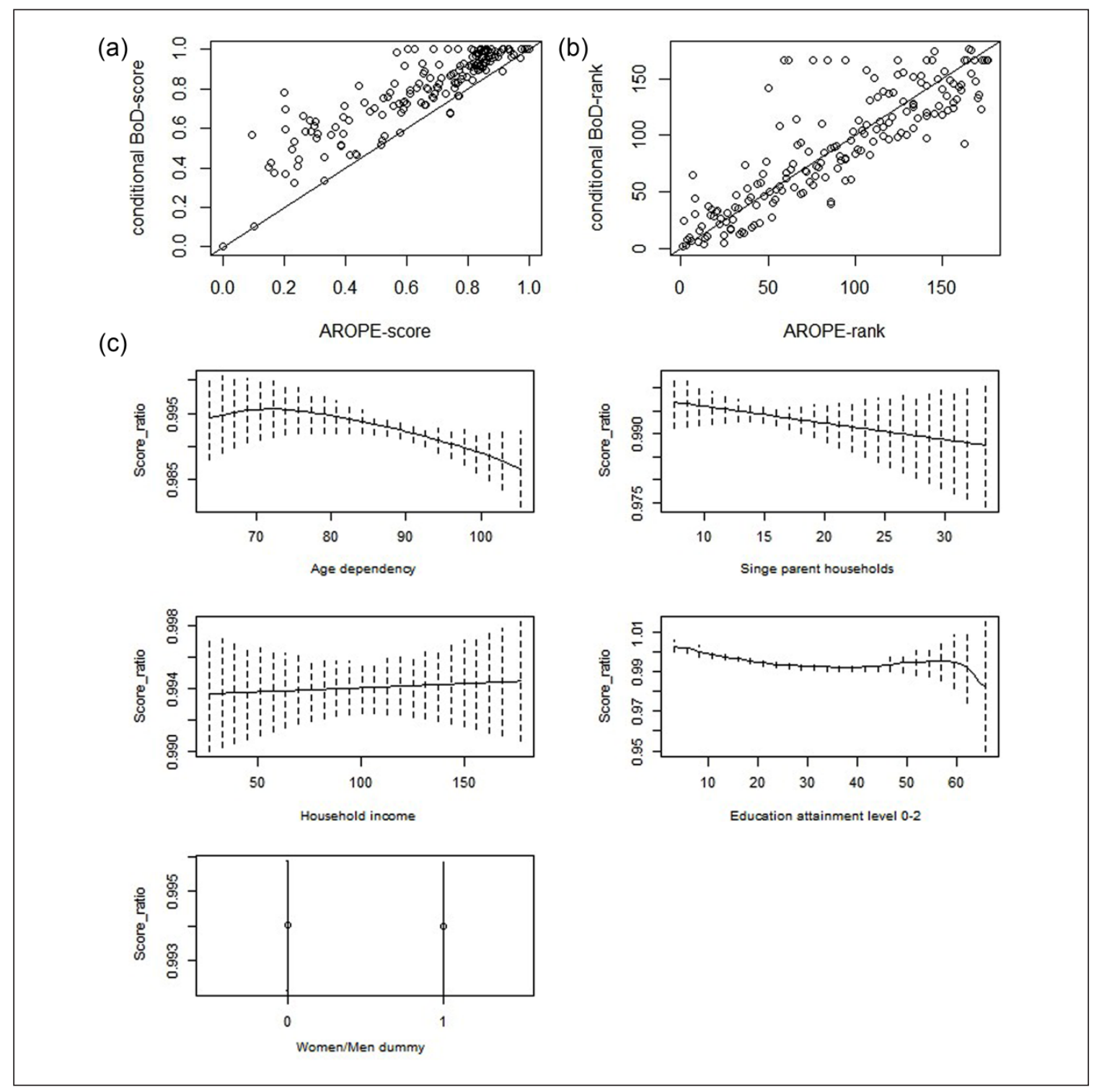

Figure I. AROPE-scores versus Social Inclusion Composite Scores.

Note: In the drawing of the maps, the AROPE index scores are normalized using

$A R O P E_{k}^{(n)}=\left(A R O P E_{k}^{\max }-A R O P E_{k}\right) /\left(A R O P E_{k}^{\max }-A R O P E_{k}^{\min }\right)$ and the conditional BoD-estimated social inclusion scores are normalized by $C l_{k}^{(n)}=\left(C I_{k}-C l_{k}^{\min }\right) /\left(C l_{k}^{\max }-C l_{k}^{\min }\right)$. As such, normalized $A R O P E_{k}^{(n)}$ and $C l_{k}^{(n)}$ values are situated between 0 and $\mathrm{I}$, with higher values indicating a better performance in social inclusion.

the majority of the regions in their social inclusion performances is modest when favourable BoD weighting is applied. Nonetheless, the difference between the maximum and minimum estimated BoDweighted regional social inclusion composite index scores suggests that the disparity between the bestand worst-performing regions is significant. The different constructions of the AROPE rate and $\mathrm{BoD}$ indices offer an explanation for the adverse interpretations observed in the descriptive statistics. The 
AROPE rate indicates the percentage of the population in a region suffering from at least one type of poverty (as measured by the three social indicators) thus the AROPE is not simply an aggregated (equalweighted) sum of the three indicators. This method is useful insofar as identifying the proportion of the population at risk vis-à-vis those who suffer from no form of poverty or social exclusion. The BoDconstructed index scores estimate the overall social inclusion performance of a region after assigning the most favourable weighting scheme.

In the scatterplots of the AROPE-scores and ranks versus the conditional BoD-weighted social inclusion scores and ranks, each plot contains a reference $45^{\circ}$ line (to illustrate zero impact). Note that the impact of applying the most favourable weighting scheme and correcting for contextual characteristics in the conditional BoD model is clearly visible. More specifically in the scatterplot depicting scores, one clearly observes that for a large majority of the regions, the combination of $\mathrm{BoD}$ weighting and correcting for the contextual characteristics is beneficial to the social inclusion performance scores. Note, however, that for some regions the opposite holds. From this, it could be surmised that these latter regions only performed well on the AROPE-based evaluations of the regional social inclusion due to favourable contextual characteristics. Also worth noting is that there are two regions (ITG - Isole and ITG1 - Sicilia) which appear to the bottom-left of the scatterplot. These two regions are evaluated to have performed very poorly in social inclusion based on both the AROPE rate and the BoD-weighted composite index. As to the ranks, the scatterplot depicting ranks shows that generally the lower middle and lower ranked regions are among the most affected by BoD weighting and the accounting for contextual factors, while the strongest performers tend to perform strongly irrespective of whether or not the most favourable weighting scheme is applied and contextual characteristics accounted for. These results at least partially support the theories ventured in this article about the methodological difficulties in comparing the social inclusion performances of heterogeneous regions and/or countries, and that contextual characteristics have a telling impact on the ability of regions to combat poverty and social exclusion.
The remainder of this section describes and compares the AROPE and conditional BoD-weighted social inclusion scores and ranks at national level (NUTS-0-level regions) and sub-national level (NUTS-1-level and NUTS-2-level regions). The focus is first on the social inclusion performances of the national-level regions. Table 1 displays a full overview of country scores and ranks for the EU's AROPE index and the conditional BoD-weighted social inclusion composite indicator, as well as the intervening rank changes (relative to the AROPE rank). Both the AROPE and BoD-weighted indices show that the Scandinavian countries perform well in social inclusion, as does the Czech Republic, Iceland, Switzerland, and the Netherlands. The Eastern and Southern European countries typically perform poorly in social inclusion (e.g. Bulgaria, Cyprus, Greece, Croatia, Italy). The worst-performing country is Turkey. The discrepancy between the social inclusion scores of the Scandinavian and some Northern European countries versus the Southern European countries also shows in the visualization maps of the normalized versions of Eurostat's AROPE index scores and the conditional regional BoD-based social inclusion scores. Table 1 also demonstrates that at the country level the effect of applying BoD weighting and controlling for contextual characteristics is moderate. For the most part, fluctuations in rank tend to be limited in either direction. The highest changes in rank position are observed for the Czech Republic ( -10 positions), Estonia (+17 positions) and Luxembourg $(+10$ positions). Estonia's rise could be attributed to a farimproved performance evaluation of social inclusion when compared in the context of analogous peers. Luxemburg is an interesting case, and a possible interpretation for the considerable change in its ranking position could be rooted in its unconventional contextual characteristics. Luxembourg shares similar contextual characteristics to the capital regions of the wealthier European nations such as Zürich, Helsinki-Uusimaa and Stockholm, with high household income and relative low age dependency. But at the same time, Luxembourg also hosts a considerable number of single-parent households and high rates of low education attainment, relatively speaking, which are more common in regions in Eastern 


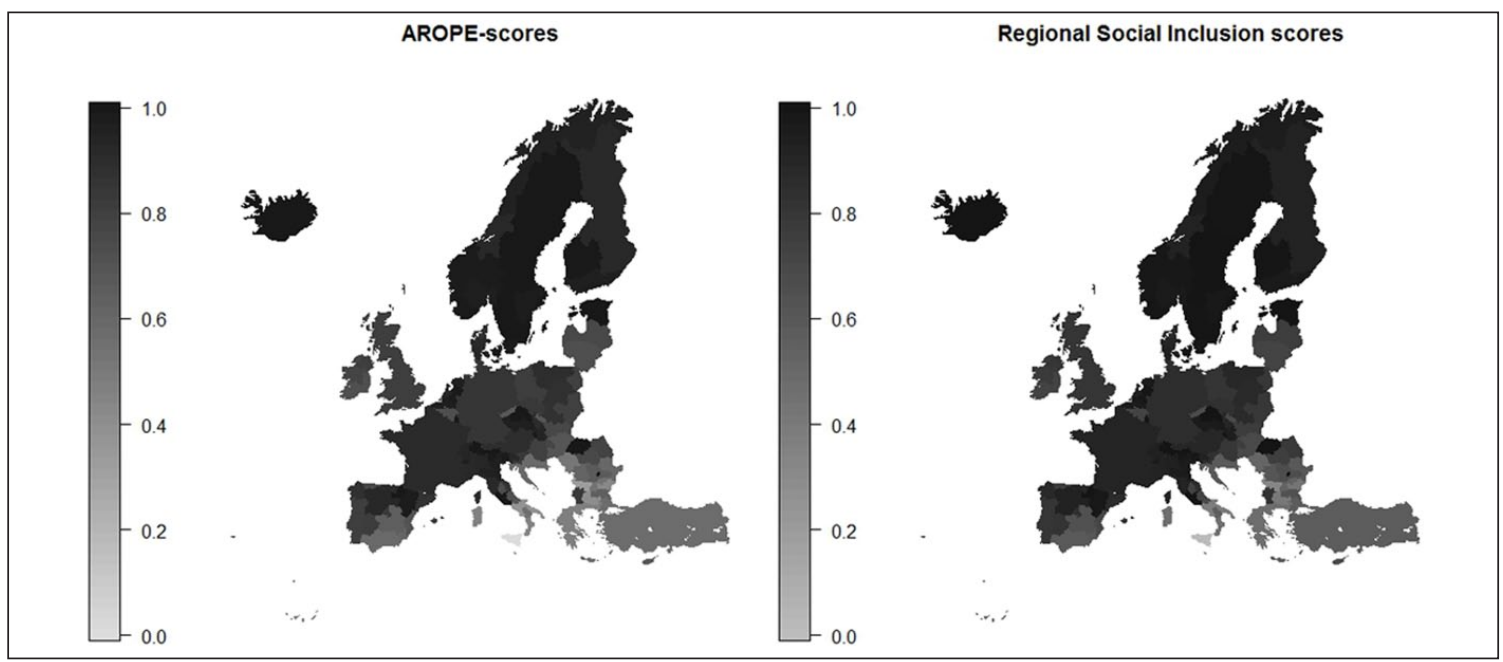

Figure 2. Scatterplots for (a) conditional BoD-weighted social inclusion performance scores vs AROPE, (b) conditional BoD-weighted social inclusion performance ranks vs AROPE-based ranks and (c) partial regression plots contextual characteristics.

and Southern Europe. For this reason, it could be that while the likes of Zurich, Helsinki and Stockholm are drawn more exclusively against regions such as themselves (with typically strong social inclusion performance) making an improved overall social inclusion performance score harder to achieve, Luxembourg's differentiation leads to a broader group of 'similar' peers with which Luxembourg's social inclusion performance reflects more positively.

To illustrate that a further regional breakdown of social inclusion performance offers a means to better understanding underlying mechanisms and implementing targeted policy responses, Table 2 displays the AROPE index and the BoD-estimated composite social inclusion scores and ranks for the NUTS-2level regions of three countries with traditionally varying regional composition: Sweden, the Czech Republic and Romania. A review of the respective index scores and ranks reveals several interesting findings. First, the Swedish regions perform relatively well in social inclusion, and more significantly, very consistently across the country in general, with a ranking range of 45 between the best- (SE11 Stockholm) and worst-performing (SE12 - Oestra Mellansverige) Swedish regions. Conversely, the Czech NUTS-2-level regions, although featuring the three top-performing regions in the entire sample (namely, CZ01 - Praha, CZ02 - Stredni Cechy and CZ05 - Severovychod), are much less consistent performers with a range of 89 rank positions between the best (CZ02 - Stredni Cechy) and worst (CZ04 Severozápad and CZ08 - Moravskoslezsko) performers. As for Romania, the AROPE and the BoD-based composite index scores and ranks reveal that Romanian regions generally perform relatively poorly in social inclusion vis-à-vis the other regions in the sample, although some regional disparity is also evident. The trends observed here correspond with the literature on regional disparity, with the Scandinavian nations considered among the most homogeneous in the EU (Weziak-Bialowolska, 2016) and the Czech Republic more divided (Förster et al., 2003). Figure 1 visualizes this difference in regional disparity, with regions in Scandinavia and some Northern European countries generally performing similarly in social inclusion and regions in Southern European and Central Eastern European countries showing more dissimilar social inclusion performances. It is also worth noting that the AROPE index scores of the NUTS-1 regions differ in summarizing the performances of the constituent NUTS-2-level regions. In particular, the AROPE index scores of the NUTS-1-level regions RO1 (Macroregiunea unu) 
and RO2 (Macroregiunea doi) are both very closely aligned to the individual performances of their NUTS-2-level regions, while the opposite stands for RO3 (Macroregiunea trei) and RO4 (Macroregiunea patru), whose AROPE index scores reconcile the disparity observed between the NUTS-2-level regions within. Another interesting finding is that the use of the most favourable weighting scheme and the correction for contextual characteristics in the evaluation of the regional social inclusion performance benefit all Swedish regions, with all Swedish regions having positive changes in rank position relative to the AROPE rank. A similar remark can be made on the Romanian regions with all but two (i.e. RO4 Macroregiunea patru and RO42 - Vest) regions showing a marked rank improvement. As to the rank changes for the Romanian regions, one interpretation here could be that most Romanian regions have particular social policy priorities and that a majority of resources and/or attention is attached to these priorities, as opposed to being spread across multiple fronts, and that when evaluated predominantly based on the performance of the focus aspects Romania is actually more successful in its social inclusion policy than suggested by the EU's AROPE index. The use of BoD weighting in the evaluation of regional social inclusion negatively impacts the index scores and ranks of all but two Czech regions (CZ01 - Praha and CZ05 - Severovýchod). The negative impact for the Czech regions indicates that the Czech regions enjoy contextual characteristics which generally dictate strong performance in social inclusion and that when compared to other regions with similar contextual conditions their social inclusion performances are actually not as strong as when taken at face value. A similarly profound effect to that of the Czech regions is found for the Romanian regions, albeit of a polarized nature. When controlling for the primarily unfavourable contextual characteristics, the estimated social inclusion performances of the Romanian regions are dramatically improved. On the premise that they are now compared to regions with similarly disadvantageous contextual conditions (thus generally poor social inclusion performance), it becomes easier to attain a higher relative ranking. Moreover, three regions (RO1 - Macroregiunea unu, RO11 Nord-Vest, and RO4 - Macroregiunea patru) are adjudged, relatively speaking, to perform very well in promoting social inclusion given their contextual circumstances.

As to the question of how regional contextual characteristics relate to BoD-estimated composite social inclusion scores, the partial regression plots in Figure 2(c) visualize the associations. In the reading of these plots, negative (positive) slopes denote a negative (positive) relationship with regional social inclusion performance. In the top tier of Figure 2(c), the plot on the left shows that age dependency relates negatively, albeit moderately, to regional social inclusion performance scores. As mentioned in the data section, youths and the elderly (0-19 and 60+) statistically tend to be more at risk of poverty and social exclusion than those of working age (20-59), validating the negative relationship observed. A small caveat to this notion is that, actually, some of the most age-dependent regions (predominantly the Scandinavian regions) also tend to have generally favourable socio-economic climates and therefore perform well in social inclusion. Due to these outcomes, the overall expected negative association of age dependency on social inclusion is partially offset, namely due to the interaction and influence of other underlying variables. Nonetheless, the presence of a high age-dependency ratio in conjunction with weaker socio-economic conditions, in general, is found to relate more negatively to social inclusion overall, hence the net-effect negative slope. Small confidence intervals around the 90 percent agedependency rate also correspond to this explanation, with the association between age dependency and regional social inclusion performance being most significant at this rate of age dependency.

The top-right plot in Figure 2(c) suggests that regions with a higher rate of single-parent households obtain lower social inclusion performance scores. However, the broad confidence intervals show that this negative association is statistically non-significant. Note, however, that there are some reasons to believe that the degree to which the singe-parent household rate relates to regional social inclusion is understated in the present analysis. One reason is spurious correlation. Upon a closer look at the data, it is possible to make an intuitive link between single-parent households and other spurious variables, such as 
religion, for example. In the generally poorly performing southern regions of Italy and Spain, singleparent households are relatively uncommon, perhaps due to the stronger catholic family values typical of these regions. Despite being relatively few, several statistical reports (Eurostat, 2016) point out that single-parent households in these countries are the most vulnerable of all single-parent households. At the other end of the spectrum, there are some regions like the Czech region Praha that have a high number of single-parent households and who also perform strongly in social inclusion. Clearly, these above trends distort the estimated overall association of single-parent households on the regional social inclusion performance scores. The middle-right plot in Figure 2(c) shows that, on average, a high level of low educational attainment in a region is negatively (be it only modestly) associated with social inclusion. A possible explanation as to why low educational attainment is only found to relate mildly to regional social inclusion is that many of the regions with the best education levels (so low rates of educational attainment 0-2) tend to be found in Eastern Europe, for example, Stredné Slovensko (Slovakia), Region Centralny and Region Poludniowy (Poland), Lithuania and Yugozapaden (Bulgaria), with the Southern continental regions (of Spain, Italy, Portugal and Greece) almost exclusively hosting the highest levels of low education attainment. Although polarized on education, both of these regional archetypes are typically weaker performers in social inclusion. This phenomenon offers some explanation for the finding that the steepest gradients of the slope appear at the tails of both ends. The left-hand plot of the middle tier of Figure 2(c) visualizes the estimated relationship between the regional average household income and the BoD-weighted social inclusion performance scores. This contextual characteristic essentially represents average wealth by an EU standard. The partial plot shows a marginally positive slope. The broad confidence intervals render the positive association as insignificant, particularly for the more extreme cases of high/low relative wealth. One possible explanation for this finding of a statistically insignificant relation could be that the AROP, one of the three social indicators of the composite social inclusion performance indicator, is determined at the national level and hence averages out more significant regional fluctuations. Nonetheless, a more significant relationship between average household income and regional social inclusion had been anticipated. Finally, the bottom tier of Figure 2(c) concerns the gender variable. The difference in social inclusion between regions with a majority of females versus regions with a majority of males according to the computations is limited and insignificant. The flat line and broad confidence intervals show that, on average, a female majority region is not predisposed to perform badly in social inclusion. It has been discussed previously that although women are generally more at risk of poverty or social exclusion based on EU averages, this effect does not necessarily translate to female-majority regions alone. Pairing gender with additional circumstances such as age, household composition or employment could be expected to yield a more significant association.

\section{Conclusion}

This article has measured regional social inclusion performances in the EU by nominally aggregating the three commonly agreed regional social indicators into a composite, summary indicator. Key objectives concerned constructing a more nuanced and balanced benchmarking framework upon which to compare the regions, as well as identifying the strongest social inclusion determinants and assessing whether the data reveal any particular areas in which regions of similar domestic conditions can learn from and emulate the better performers. The article proposed a specially tailored version of the BoD model to (1) construct composite social inclusion scores for the NUTS regions, (2) adjust them for the impact of contextual characteristics and (3) analyse the relationship of these characteristics with the regional social inclusion performance scores. The combination of these three elements is quite novel in the social inclusion literature and can be particularly useful in clarifying best-practice principles for the social policy-making community.

The BoD-based evaluations of regional social inclusion performances in the EU offer a number of interesting findings. A general theme in the estimated BoD scores and ranks highlights the Scandinavian countries and the Central European 
(the Czech Republic and Switzerland) to house the most socially inclusive regions in the sample, while the Continental and Balkan States (especially Italy, Bulgaria and Greece) tend to have the worst-performing regions in the sample. The results of the BoD study also show that there is a great deal of heterogeneity among same-country regions throughout Europe, as is commonly held in the literature. It was evidenced that many regions have a lot of catching up to do to achieve the level of social inclusion performance of the better-performing regions of their nation, even with their most flattering weighting scheme applied and differences in contextual conditions accounted for. Results also show that NUTS regions with low education levels and high age dependency on average perform less strongly in social inclusion.

Before concluding this article, it is important to make some critical remarks about the present study and topics for further research. First, there are potential reservations about the contextual variables in the present study, especially in light of the fact that welldocumented determinants such as single-parent households, which is statistically upheld as a vital social exclusion determinant, are found to be only limitedly associated with regional social inclusion performance. An important point to consider with the social inclusion determinants is that they are largely considered on an EU level and relative to the EU average AROPE. So while the net effect of belonging to particular group on the likelihood of being at risk is clear on a European level, the outcome (certainly) varies from region to region. Moreover, the BoD model as applied in this article is unable to directly process the interaction between the selected contextual variables or their interaction with other external socio-economic circumstances. More detailed quantitative and qualitative analysis to this end represents a worthwhile direction to develop this research.

The lack of a complete data set at NUTS-2 level (for a number of Member States, including France, Germany and the United Kingdom) represents another significant drawback to a study of this nature, which seeks to provide a comprehensive regional analysis of EU social inclusion performance. As discussed before, currently, the disclosure of regional data has not (yet) been made compulsory by the European Commission, and as a result, several Member States do not disclose NUTS-2-level social inclusion data (or even NUTS-1-level data). If the disclosure of regional social inclusion data were to become compulsory, or more Member States decided to collect and disclose regional social inclusion data, it would be interesting to repeat the analysis using a more complete regional social inclusion data set. Another interesting research subject would be to apply the proposed framework in the evaluation of regional social inclusion across and/or within other (non-EU) countries (e.g. in the study of social inclusion at state level or even county level in the United States). A primary attraction for such a study lies in the ability to examine the links between regional contextual characteristics and social inclusion performances and whether this varies across (groups of) countries/regions and/or cultures. Another possible avenue for further research concerns the issue of omitted variable bias, which potentially plays a role in the results of this analysis. In particular, due to issues of data availability, we were not able to account for perhaps some of the most significant regional contextual characteristics in the estimation of the composite social inclusion performance scores. Examples of possibly interesting contextual characteristics, as previously mentioned, could be regions' labour markets, migration, urbanization and rate of health/disability. Therefore, as a suggestion for future studies, it would be interesting to expand or refine the selection of regional contextual characteristics.

\section{Acknowledgements}

This paper is an offshoot of the Impulsproject IMP/14/011 of the KU Leuven (Belgium).

\section{Funding}

The author(s) received no financial support for the research, authorship and/or publication of this article.

\section{Notes}

1. Note that this flexibility somewhat complicates the measurement and evaluation of social inclusion progress with differences between supranational and national goals influencing the social policy choices and activities. 
2. Further debate on confidence intervals (CIs) is available in the Organisation for Economic Co-operation and Development (OECD) Handbook on constructing composite indicators of Nardo et al. (2008).

3. Several studies have attempted to create multidimensional poverty and social exclusion indices to capture the various monetary and non-monetary aspects - for which readers can refer to, among others, Alkire and Foster (2011), Chakravarty and D'Ambrosio (2006), Nolan and Whelan (2007), Pasha (2017), Ravallion (2011) and Weziak-Bialowolska (2016).

4. The NUTS classification (Nomenclature of territorial units for statistics) is a hierarchical system dividing up the economic territory of the European Union (EU) for the purpose of the collection, development and harmonization of European regional statistics; socio-economic analyses of the regions; and framing of EU regional policies.

5. The nine items concern the ability to (1) pay rent or utility bills; (2) keep the home adequately warm; (3) face unexpected expenses; (4) eat meat, fish or a protein equivalent every other day; (5) afford a week's holiday away from home once a year; (6) buy a car; (7) buy a washing machine; (8) buy a colour TV; or (9) buy a mobile phone.

6. More technically, the convergence rate of the conditional benefit-of-the-doubt (BoD)-based estimator for the regional social inclusion performance scores decreases when (1) the number of observations in the sample set decreases, all else being equal, and (2) the number of continuous environmental variables increases, ceteris paribus (for more on this problem in robust and conditional non-parametric models, see Cazals et al., 2002; Jeong et al., 2010). Given the paper's interest of measuring regional social inclusion performance thereby correcting for differences in the regions' contextual characteristics, it is of particular interest to include a sufficient number of observations in the data set.

7. A similar remark holds for the other EU Member States with no regional social inclusion data such as France (regions in the North, North-East and South showing higher rates of poverty and social exclusion as compared to the regions in the West and SouthWest), Portugal (regions Alentejo, Açores and central and northern Portugal showing higher rates of poverty and social exclusion) and Turkey (most of the developed regions being located in the Western part of Turkey and the least developed regions being in the east of Turkey).

8. The choice for using a dichotomous gender variable was to prevent a too low discriminatory power in the analysis. However, in case more regional data and hence observations would be available, it would be best to use a continuous gender measure, for example, the percentage of women in the regional population, as contextual characteristic in the analysis.

9. More technically, the robust, conditional BoD model involves executing a Monte Carlo simulation procedure in which $B$ iterations are performed (with $B$ a large number, in casu 1000). Each iteration involves two steps. In the first step, a subset of regions with contextual characteristics similar to the ones of the evaluated region $k$ are drawn (with replacement) from the full sample of $N$ regions, with the probability of being drawn depending on the degree of similarity in terms of the regions' contextual characteristics. In the second step, the BoD model as in equation (1) with the additional weight restrictions is applied. The conditional composite social inclusion score is then computed as the average value of these $B$ composite performance scores (for more technical details, we refer the interested reader to Daraio and Simar, 2007).

10. For a more comprehensive discussion of the visualization procedure, see Daraio and Simar (2007) and Bădin et al. (2012).

11. A quick view at the optimal BoD-based importance weights for the regions as in Supplementary Appendix 1 learns that BoD-obtained importance weights for the social inclusion indicators can be quite diverse without violating the additional weight restriction of minimal importance weight for the indicators being 10 percent. This illustrates the role BOD weighting plays in the measurement of regional social inclusion performances, however, only within the a priori defined confines.

12. The at-risk-of-poverty or social exclusion (AROPE) is in essence a 'bad' as it measures social exclusion across three dimensions, whereas the conditional regional social inclusion composite scores is a 'good' as it measures social inclusion across the three same dimensions. Therefore, to enhance comparability, in the drawing of the maps, both the AROPE index scores and the conditional regional social inclusion composite scores are normalized such that they both measure social inclusion.

\section{References}

Alkire, S. and Foster, J. (2011) 'Counting and Multidimensional Poverty Measurement', Journal of Public Economics 95(7-8): 476-87.

Armstrong, K. (2012) 'EU Social Policy and the Governance Architecture of Europe 2020', European Review of Labour Research 18(3): 285-300. 
Atkinson, T. (2002) 'Social Inclusion and the European Union', Journal of Common Market Studies 40(4): 625-43.

Atkinson, T., Marlier, E. and Nolan, B. (2004) 'Indicators and Targets for Social Inclusion in the European Indicators and Targets for Social Inclusion in the European Union', Journal of Common Market Studies 42(1): 47-75.

Bădin, L., Daraio, C. and Simar, L. (2012.) 'How to Measure the Impact of Environmental Factors in a Nonparametric Production Model', European Journal of Operational Research 223(3): 818-33.

Béland, D. (2007) 'Ideas and Institutional Change in Social Security: Conversion, Layering, and Policy Drift', Social Science Quarterly 88(1): 20-38.

Cazals, C., Florens, J.P. and Simar, L. (2002) 'Nonparametric Frontier Estimation: A Robust Approach', Journal of Econometrics 106(1): 1-25.

Chakravarty, S.R. and D' Ambrosio, C. (2006) 'The Measurement of Social Exclusion', Review of Income and Wealth 52(3): 377-98.

Cherchye, L., Moesen, W. and Van Puyenbroeck, T. (2004) 'Legitimately Diverse, Yet Comparable: On Synthesizing Social Inclusion Performance in the EU', Journal of Common Market Studies (JCMS) 42(5): 919-55.

Cherchye, L., Moesen, W., Rogge, N. and Puyenbroeck, T. (2007) 'An Introduction to 'Benefit of the Doubt' Composite Indicators', Social Indicators Research 82(1): 111-45.

Coromaldi, M. and Zoli, M. (2012) 'Deriving Multidimensional Poverty Indicators: Methodological Issues and an Empirical Analysis for Italy', Social Indicators Research 107(1): 37-54.

Daraio, C. and Simar, L. (2007) Advanced Robust and Nonparametric Methods in Efficiency Analysis: Methodology and Applications (Studies in Productivity and Efficiency). New York: Springer Science + Business Media.

European Commission (1992) 'Towards a Europe of Solidarity: Intensifying the Fight against Social Exclusion, Fostering Integration', Communication from the Commission, $\operatorname{COM}(92) 542$ final, 23 December, available at http://aei.pitt.edu/4819/1/4819.pdf.

Eurostat (2016) 'Smarter', Greener, More Inclusive Indicators to Support the Europe 2020 Strategy' (2016 Edition), available at http://ec.europa.eu/eurostat/documents/3217494/7566774/KS-EZ-16-001EN-N.pdf/ac04885c-cfff-4f9c-9f30-c9337ba929aa

Ferrera, M., Matsaganis, M. and Sacchi, S. (2002) 'Open Coordination against Poverty: The New EU 'Social
Inclusion Process', Journal of European Social Policy 12(3): 223-39.

Förster, M., Jesuit, D. and Smeeding, T. (2003) Regional Poverty and Income Inequality in Central and Eastern Europe. Luxembourg: LIS Cross-National Data Center.

Giambona, F. and Vassallo, E. (2014) 'Composite Indicator of Social Inclusion for European Countries', Social Indicators Research 116(1): 269-93.

Guio, A., Fusco, A. and Marlier, E. (2010) 'Risk Factors of Income Poverty and Material Deprivation in Belgium and Regions', IWEPS: Institut Wallon De L'evaluation, De La Prospective Et De La Statistique, Namur, September 2010.

Jeong, S., Park, B. and Simar, L. (2010) 'Nonparametric Conditional Efficiency Measures: Asymptotic Properties', Annals of Operations Research 173(1): 105-22.

Longford, N.T., Pittau, M.G., Zelli, R. and Massari, R. (2010) 'Measures of Poverty and Inequality in the Countries and Regions of EU', Society for the Study of Economic Inequality, ECINEQ 2010-182, available at http://www.ecineq.org/milano/wp/ ecineq2010-182.pdf.

Madanipour, A., Shucksmith, M. and Talbot, H. (2015) 'Concepts of Poverty and Social Exclusion in Europe', Local Economy 30(7): 721-41.

Maitre, B., Nolan, B. and Whelan, C. (2013) 'A Critical Evaluation of the EU 2020 Poverty and Social Exclusion Target: An Analysis of EU-SILC 2009', Amsterdam Institute for Advanced Labour Studies (AIAS), GINI Discussion Paper 79, available at http://gini-research.org/system/uploads/580/original/79.pdf?1385131257.

Nardo, M., Saisana, M., Saltelli, A., Tarantola, S., Hoffman, A. and Giovannini, E. (2008) Handbook on Constructing Composite Indicators: Methodology and User Guide. Paris; Ispra: Organisation for Economic Cooperation and Development; Joint Research Centre of the European Commission.

Nolan, B. and Whelan, C.T. (2007) 'On the Multidimensionality of Poverty and Social Exclusion', in J. Micklewright and S. Jenkins (eds) Inequality and Poverty Re-Examined. New York: Oxford University Press, 146-165.

Pasha, A. (2017) 'Regional Perspectives to the Multidimensional Poverty Index', World Development 94: 268-85.

Ravallion, M. (2011) 'On Multidimensional Indices of Poverty', Journal of Economic Inequality 9(2): 235-48. 
Robinson, P. and Oppenheim, C. (1998) Social Exclusion Indicators: A Submission to the Social Exclusion Unit. Londres: Institute for Public Policy Research.

Rogge, N. (2017) 'Measuring the Impact of the Economic Crisis on the Level of Change in EU Social Inclusion: Period 2005-2012', Journal of Productivity Analysis 47(2): 103-16.

Rogge, N. and Konttinen, E. (2017) 'Social Inclusion in the EU since the Enlargement: Progress or Regress?' Social Indicators Research 135: 563-84.

Room, G.J. (1999) 'Social Exclusion, Solidarity and the Challenge of Globalization', International Journal of Social Welfare 8(3): 166-74.

Social Protection Committee (2011) 'The Social Dimension of the Europe 2020 Strategy', Directorate-General for Employment, Social Affairs and Inclusion, available at http://www.eapn.eu/images/stories/docs/ EAPN-position-papers-and-reports/2011-briefingnote-europe-2020-en-final.pdf

Social Protection Committee (2012) Social Protection Performance Monitor (SPPM) - Methodological Report by the Indicators Sub-group of the Social Protection Committee. Report of Social Protection
Committee (RDG Employment, Social Affairs \& Inclusion, European Commission), 17 October.

Social Protection Committee (2015) Social Protection Committee Indicators Sub-group Portfolio of EU Social Indicators for the Monitoring of Progress Towards the EU Objectives for Social Protection and Social Inclusion. Luxembourg: Publications Office of the European Union.

Stewart, K. (2003) 'Monitoring Social Inclusion in Europe's Regions', Journal of European Social Policy 134: 958-87.

Weziak-Bialowolska, D. (2016) 'Spatial Variation in EU Poverty with Respect to Health, Education and Living Standards', Social Indicators Research 125(2): 451-79.

Whelan, C.T. and Maître, B. (2013) 'Material Deprivation, Economic Stress, and Reference Groups in Europe: An Analysis of EU-SILC 2009', European Sociological Review 29(6): 1162-74.

Zeitlin, J. (2008) 'The Open Method of Co-ordination and the Governance of the Lisbon Strategy', Journal of Common Market Studies (JCMS) 46(2): 436-50. 